\title{
Development of Chitosan Silver Nanocomposites: Its Characteristic Study and Toxicity Effect against 3T3-L1 Cell Line
}

\author{
Jesteena Johney ${ }^{*}$ (D) S. Radhai Sri' and R. Ragunathan ${ }^{3}$ \\ ${ }^{1}$ Department of Food and Nutrition, Research and Development Centre, Bharathiar University, \\ Coimbatore - 641 046, Tamil Nadu, India. \\ ${ }^{2}$ Department of Food Processing and Technology, PSG College of Arts and Science, \\ Coimbatore - 641 014, Tamil Nadu, India. \\ ${ }^{3}$ Department of Biotechnology, Centre for Bioscience and Nanoscience Research, Eachanari, \\ Coimbatore - 641 021, Tamil Nadu, India.
}

\begin{abstract}
Nanocomposite from the natural source is opened a wide area for the researchers to find a natural remedy to replace the chemicals or harmful products in all the fields of agricultural, food and medical fields. Here the biopolymer (chitosan) was extracted from the two white rot fungi of Pleurotus floridanus and Pleurotus djamor, and biologically synthesized with $1 \mathrm{mM} \mathrm{AgNO}$ solution. Synthesized chitosan nanocomposite was characterized with UV-Visible study, FTIR, FESEM, XRD, EDAS for the confirmation based upon the peaks, functional group, crystalline nature, size, morphology and the percentage of elements respectively. Toxicity study was carried out using 3T3 L1 (Mouse embryo fibroblast Cell Line) normal Cell Line to find out the cytotoxicity effect of the chitosan nanocomposite and found that the nanocomposites were non toxic to the Cell Line.
\end{abstract}

Keywords: Nanocomposite, FESEM, XRD, EDAS, 3T3- L1 Cell Line

\footnotetext{
*Correspondence: jesticbnr@gmail.com

(Received: November 3, 2021; accepted: January 13, 2022)

Citation: Johney J, Sri SR, Ragunathan R. Development of Chitosan Silver Nanocomposites: Its Characteristic Study and Toxicity Effect against 3T3-L1Cell Line. J Pure App/ Microbiol. 2022;16(1):494-502. doi: 10.22207/JPAM.16.1.47

(C) The Author(s) 2022. Open Access. This article is distributed under the terms of the Creative Commons Attribution 4.0 International License which permits unrestricted use, sharing, distribution, and reproduction in any medium, provided you give appropriate credit to the original author(s) and the source, provide a link to the Creative Commons license, and indicate if changes were made.
} 


\section{INTRODUCTION}

From the middle of $20^{\text {th }}$ century, the world's population has engaged to find out a better remedy to treat various diseases caused by microorganisms. Improper use of the chemicals in clinical treatment in living animals has prompted the different of pathogens that are resistant to the variety of compounds and less effect in treatment. Significant changes in the generation of bacteria to the antibiotic available on the market have been observed, ${ }^{1,2}$ Pharmaceutical industries are facing issues for finding new or innovative drug making because of the changes of genetic elements of the pathogens. This is opening a new way to find an antimicrobial compound.

Currently, nanotechnology and nanomaterials are getting more priority in all the fields of agriculture, pharmacy, food industry, etc. Owing to the unique property of the nanoparticle, various methods and research are going on in all the fields. Nanoparticles are commonly established in the perspective of nanotechnology and Nanoscience is a unit of scientific measurement from the nanometre of $1-100 \mathrm{~nm}$ in size. ${ }^{3}$ In current occasion, metallic nanoparticles are showing unique properties and activities such as physical, biological and chemical synthesising. Thus this have more subject of extensive research in recent years. ${ }^{4,5}$

Metallic nanoparticles show signs of different properties in their size and shape dependent. Silver nanoparticle has high therapeutic potential value because of its good antimicrobial activity. This nanoparticle has high antimicrobial activity while using very small concentration. It is also identified as good anti-cancer agent. ${ }^{6}$ Bio synthesizing methods are employing natural compounds such as microorganism, animal source, plants, polysaccharide etc. are crop up as simple and alternative source as silver nanoparticle. ${ }^{7}$

Chitosan is a polysaccharide extracted from the chitin by deacetylation process. Most of the chitosan extraction is from crab or shrimp. ${ }^{8}$ Apart from marine source plants, fungi are rich in chitosan. Pleurotus spp. are most popular edible mushroom because of its temperature from $15-30^{\circ} \mathrm{C}$, easy cultivation procedure, different substrate of agro residue, feed, vitamins, waste and weed for production of food, enzymes in addition to their waste detoxification properties and degradation. ${ }^{9}$ Edible fungi has biological effects as it contains important bioactive compounds. Mushrooms are using as a food before 2000 years ago because of the medicinal importance. 200 species of mushrooms are used as functional food in the world, ${ }^{10}$ but only 35 to 40 species are commercially cultivated for various purposes. ${ }^{11}$ The current research was done to synthesize the chitosan silver nanocomposite from the Pleurotus spp. (Pleurotus floridanus and Pleurotus djamor) characterization and cytotoxicity effect against 3T3-L1 Cell Line.

\section{MATERIALS AND METHODS}

Sub culturing and extraction of chitosan from Pleurotus spp.

Pleurotus spp. was collected from Tamilnadu Agricultural University and subcultured to Potato Dextrose Agar. Molecular identification was done and submitted to NCBI gene bank (Pleurotus floridanus- MG324371.1 and Pleurotus djamor- MG328900.1). ${ }^{12}$ After seeding, the plate was incubated at $30^{\circ} \mathrm{C}$ for 12 days. The grown fungi mycelium was reinoculated in MGYP medium and the chitosan was extracted after deproteinization, demineralisation and deacetylation. ${ }^{13}$

Preparation of chitosan nanocomposite solution

The extracted chitosan was dried and $1 \%$ of the chitosan solution was prepared in $2 \%$ of acetic acid $(2 \mathrm{ml}$ acetic acid and $98 \mathrm{ml}$ distilled water) and glucose (2g in $100 \mathrm{ml}$ distilled water). The mixture was incubated in magnetic stirrer for 30 minutes for mixing and added $1 \%$ of $\mathrm{NaOH}^{14}$ Then it was used for the silver nanoparticle synthesizing by mixing equal volume of $1 \mathrm{mM}$ silver nitrate. After blending, sample was incubated for 24 to $48 \mathrm{hrs}$ at room temperature.

\section{Characterisation of chitosan nanocomposites}

Synthesized nanocomposites were primarily identified with color change from light brown to dark brown. The nanocomposite was analyzed by UV-Visible spectrophotometer from $300-600 \mathrm{~nm}$ using Labtronics LT 291. The functional group responsible for the synthesising was identified with FTIR from $4000^{\mathrm{cm}-1}$ to $400^{\mathrm{cm}-1}$ (Shimadzu). The size and morphology were identified with MIRA 3 TESCAN SEM- Field Emission Scanning Electron Microscope. ${ }^{15}$ Percentage of 
the elements and the crystalline nature of the nanocomposites were identified with XRD and EDAS analysis using PAN analytical instrument. ${ }^{16}$ Toxicity study

MTT Assay method 12, (3-(4,5Dimethylthiazol-2-yl)-2,5diphenyletrazoliumbromide) was used for toxicity study against 3T3-L1 (Mouse embryo fibroblast-Normal Cell Line) Cell Line. The cells were grown in DMEM medium supplemented with $10 \%$ fetal bovine serum albumin and incubated in $\mathrm{CO}_{2}$ incubator with $5 \% \mathrm{CO}_{2}$ and $70-80 \%$ of humidity at $37^{\circ} \mathrm{C}$ for 24- $72 \mathrm{hrs}$. Cells was primarily confirmed by using inverted microscope (Unicon) and the Cell Line was transferred to 96 well plate. $100 \mu$ l of the Cell Line was mixed with different concentration of the nanocomposite $(25,50,100,200,400 \mu \mathrm{g} / \mathrm{ml})$ and incubated for $24 \mathrm{hrs}$ in $\mathrm{CO}_{2}$ incubator $\left(5 \% \mathrm{CO}_{2}\right)$ at $37^{\circ} \mathrm{C} .100 \mu \mathrm{l}$ of blank (DMSO), control (only Cell Line) and standard control (drug-doxorubicin-12.5 $\mu \mathrm{M}$ ) was also maintained in 96well plate (with triplicates). After $24 \mathrm{hrs}$ of incubation, the cells was washed with $50 \mu \mathrm{l}$ of DMSO and trypsin. To the washed cells, $20 \mu \mathrm{l}$ of MTT dye was added and again incubated in $\mathrm{CO}_{2}$ incubator for $24 \mathrm{hrs}$. After incubation, using ELISA (Robonik-Readwell
Touch Elisa Plate Analyser) reader the OD value was measured at $570 \mathrm{~nm}$, calculated the viability (formula: Viability $=100 \times$ (Control OD-Sample OD)/ Control OD) and $\mathrm{IC}_{50}$ value using linear regression equation $(\mathrm{Y}=\mathrm{Mx}+\mathrm{C}$, here $\mathrm{Y}=50, \mathrm{M}$ and $\mathrm{C}$ values from the Viability graph).

\section{RESULTS AND DISCUSSION \\ Characterization of chitosan nanocomposites UV-Visible study}

As shown in Fig. 1, the extracted chitosan (11.5g of chitosan was obtained from $100 \mathrm{~g}$ of Pleurotus mycelium) was used for the synthesizing of silver nanocomposite. After $24 \mathrm{hrs}$ of incubation the synthesized nanocomposite was characterized primarily with the color change (dark brown color observed).

UV-Visible study was done to determine the optical properties of the chitosan nanocomposite, which is widely used technique for the characterization of the various nanoparticle. Silver nanocomposite plasmon peak was observed at $460 \mathrm{~nm}$ (Fig. 2), which indicated the presence of silver nanocomposite. Similar results were observed for the synthesis of chitosan silver nanoparticle extracted from the crustacean

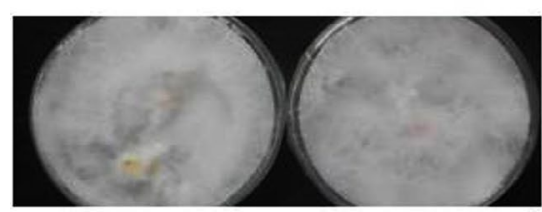

PDA contain Pleurotus spp.
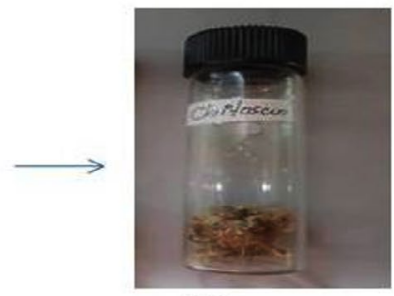

Chitosan

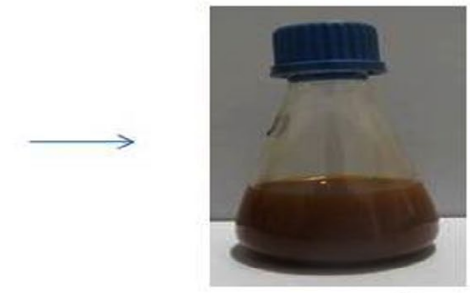

nanocomposite

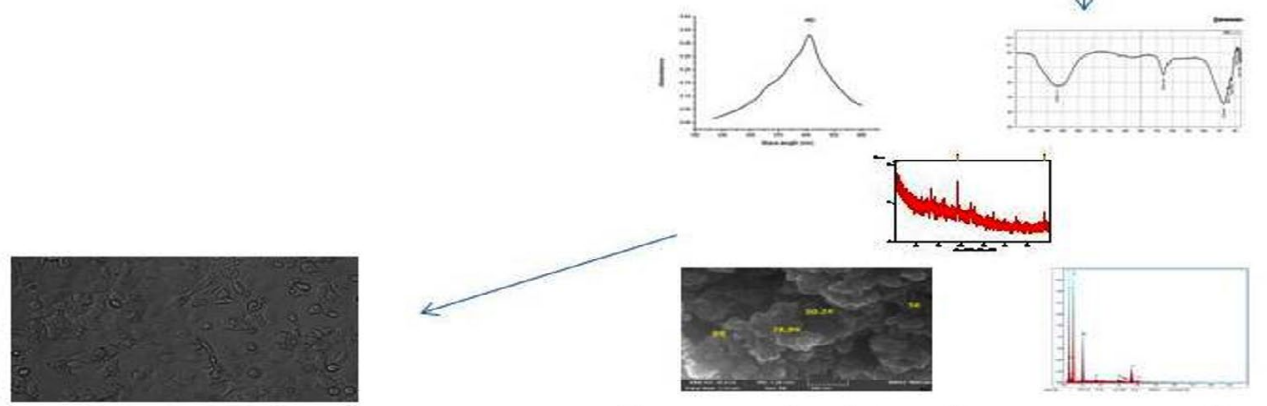

Toxicity study

Fig. 1. Graphical representation of the research work. 
sample at $450 \mathrm{~nm} .{ }^{17}$ It has been reported that the $400 \mathrm{~nm}$ above peaks may be related to synthesis from natural sources tend to present two or more populations with diverse proportions and the presence of $\mathrm{NaOH}$ in the synthesis. ${ }^{18}$

UV-Visible spectroscopy shown peaks at $390 \mathrm{~nm}$ and $420 \mathrm{~nm}$ for the chitin and chitosan silver nanoparticle extracted from fungi F.solani. ${ }^{19}$ Honary et al, synthesised with different molecular weight chitosan and observed the plasmon peaks between $400-420 \mathrm{~nm} .{ }^{20}$ Synthesized chitosan silver nanoparticle using s-triazinylbis (2-aminomethylpyridine) and s-triazinylbis (8-oxyquinoline) got a high peak at $420 \mathrm{~nm} .{ }^{21}$ In another study chitosan silver nanoparticle from Saccharum officinarum exhibited peak at $460 \mathrm{~nm} .{ }^{22}$ These findings are co inside with our results.

\section{FTIR}

The synthesized silver nanocomposite solution was subjected to Fourier Transform Infrared spectroscopy study, to identify the functional groups. Obtained peaks are

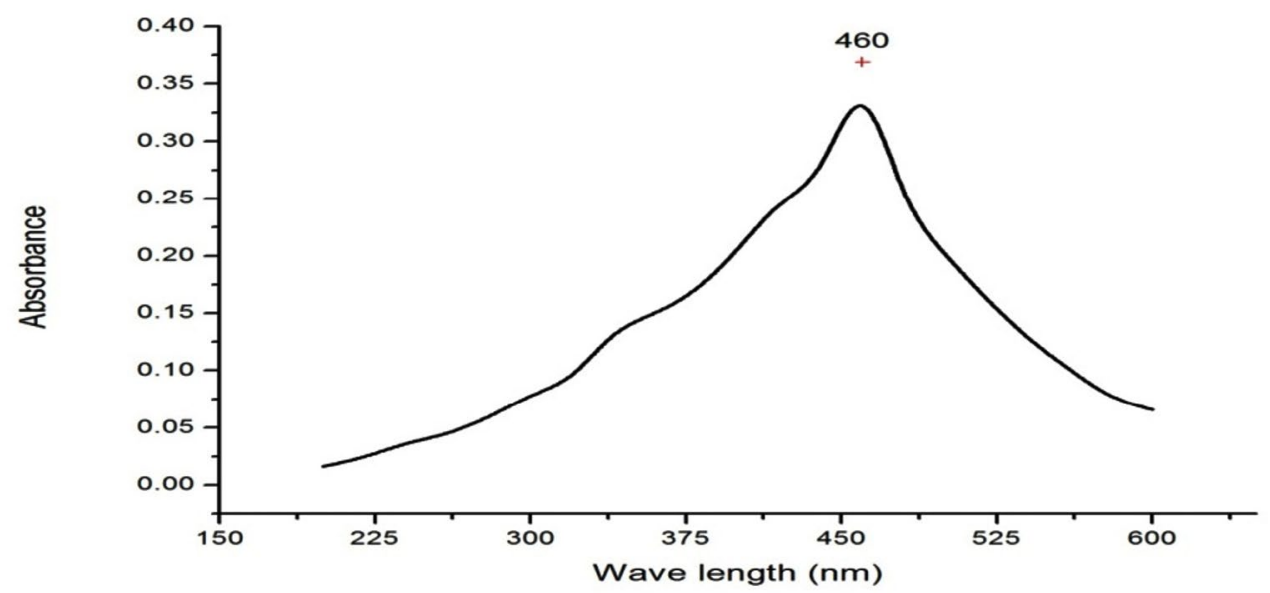

Fig. 2. UV-Visible spectroscopy analysis.

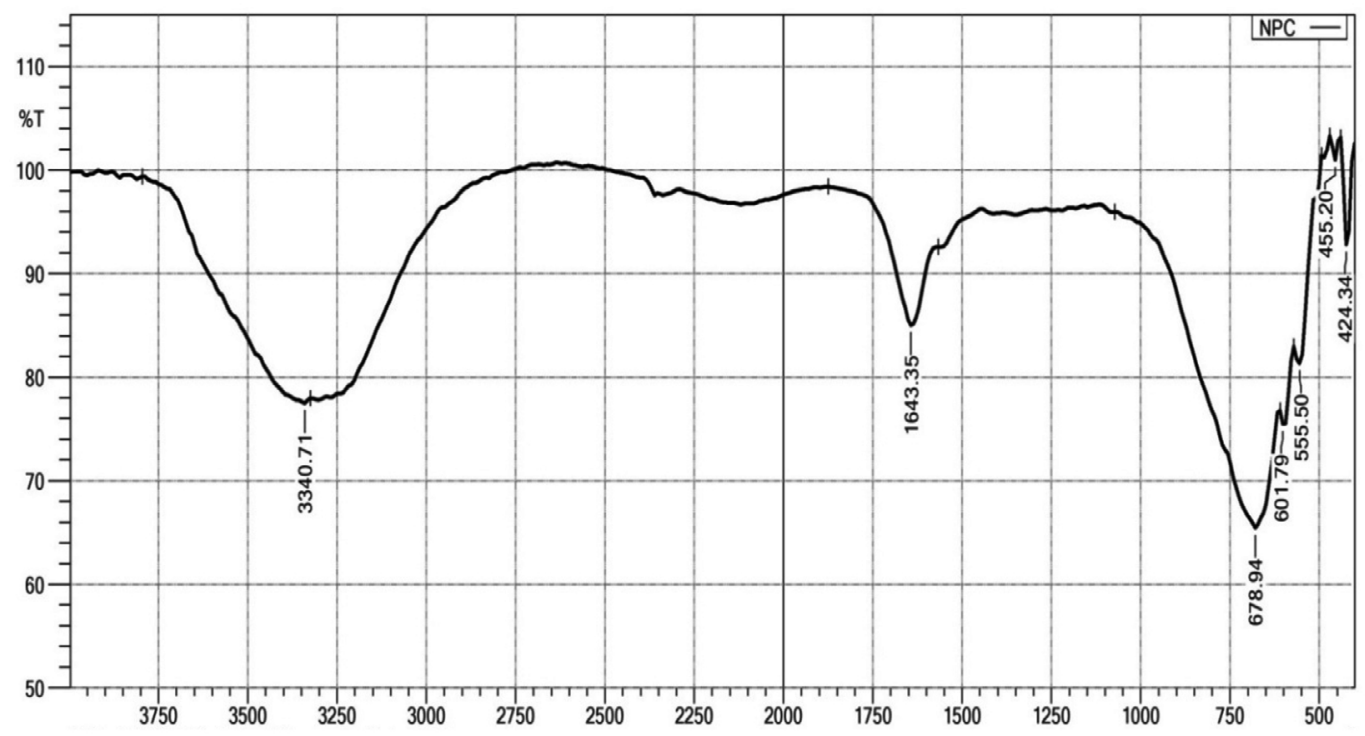

Fig. 3. FTIR study of the chitosan nanocomposite. 
$3340^{\mathrm{cm}-1}$ (alcohol OH stretch), $1643^{\mathrm{cm}-1}(\mathrm{C}=\mathrm{C}$ alkene), $678^{\mathrm{cm}-1}$ and $601^{\mathrm{cm}-1}(\mathrm{C}-\mathrm{Cl}), 555,455$ and $424^{\mathrm{cm}-1}$ (C-I strong bond). ${ }^{23}$ FTIR spectrum peaks at $3431,1635,1390,1274,556^{\mathrm{cm}-1}$, which represent amide linkage group and band at $1635^{\mathrm{cm}-1}$ is an amide I bond. The peak at $1390^{\mathrm{cm}-1}$ is a $\mathrm{CH}_{3}$, and at $1274^{\mathrm{cm}-1}$ corresponded to single bond stretching of carboxylic acids, the peak at $3431^{\mathrm{cm}-1}$ corresponded to the stretch $\mathrm{OH}$ groups. Peak at $556^{\mathrm{cm}-1}$ belonged to the single bond $\mathrm{Br}$ stretch of alkyl halides (Fig.3). In the IR spectrum, $3500-3200^{\mathrm{cm}-1}$ was more asymmetric and indicated the existence of $\mathrm{OH}$ and $\mathrm{NH} 2$ groups. ${ }^{24}$ Peak at $1680^{\mathrm{cm}-1}$ in was due to oscillations of $\mathrm{C}=\mathrm{O}$ in amino groups and acetyl amino groups, i.e. a deacetylated appearance of chitin. $\mathrm{C}-\mathrm{CH}_{3}$ deformation in amide group observed at $1384^{\mathrm{cm}-1} .1050^{\mathrm{cm}-1}$ indicated the saccharide after the absorption of the silver ions. FTIR peaks from 650 to $400^{\mathrm{cm}-1}$ is denoting the reducing deed of chitosan and precipitation of metallic silver and formation of silver nanocomposites. ${ }^{25}$

FESEM

Examination of FESEM image revealing that the synthesized chitosan silver nanocomposite has spherical in shape and the size from 50.24 to 88nm (Fig. 4).

Sharanya Devadiga et al, found $96.3 \mathrm{~nm}$ size of the chitosan silver nanocomposites, extracted from the crustacean sample. ${ }^{17}$ Another study reported that the synthesised chitosan composite had $16 \mathrm{~nm}$ in size with more porous upon cross linking nature obtained from fungi. ${ }^{26}$ Nanoparticles with less than $100 \mathrm{~nm}$ in diameter were attracting with the efficiency of the sample in the various field of industry. The nanoparticles size was showing difference in their materials, as a results of quantum confinement, particle size, large surface area etc. ${ }^{7}$

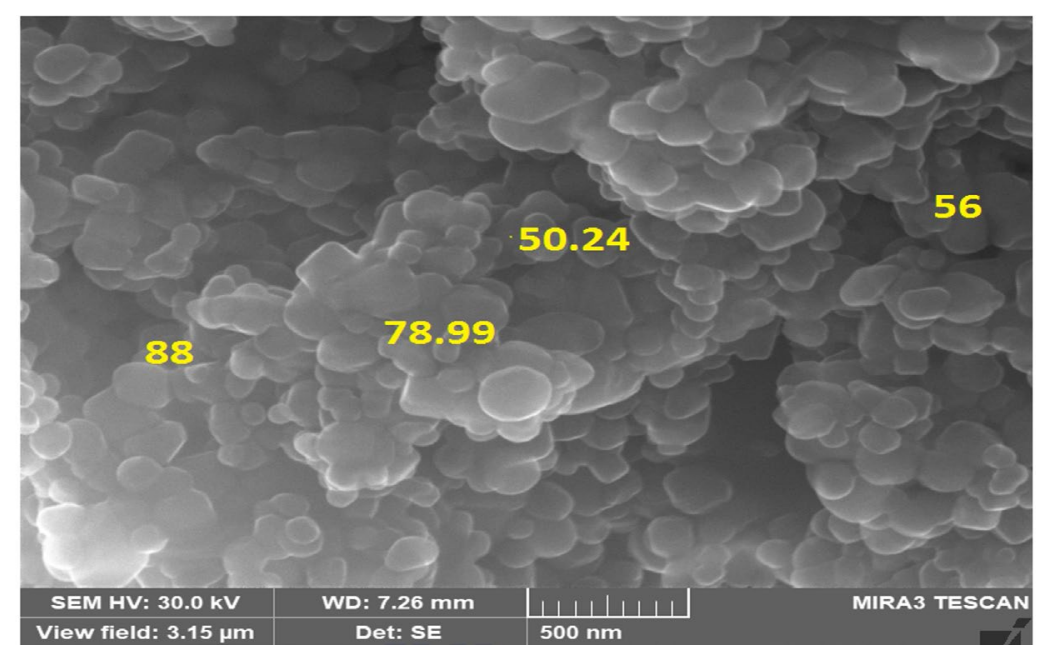

Fig. 4. FESEM image.

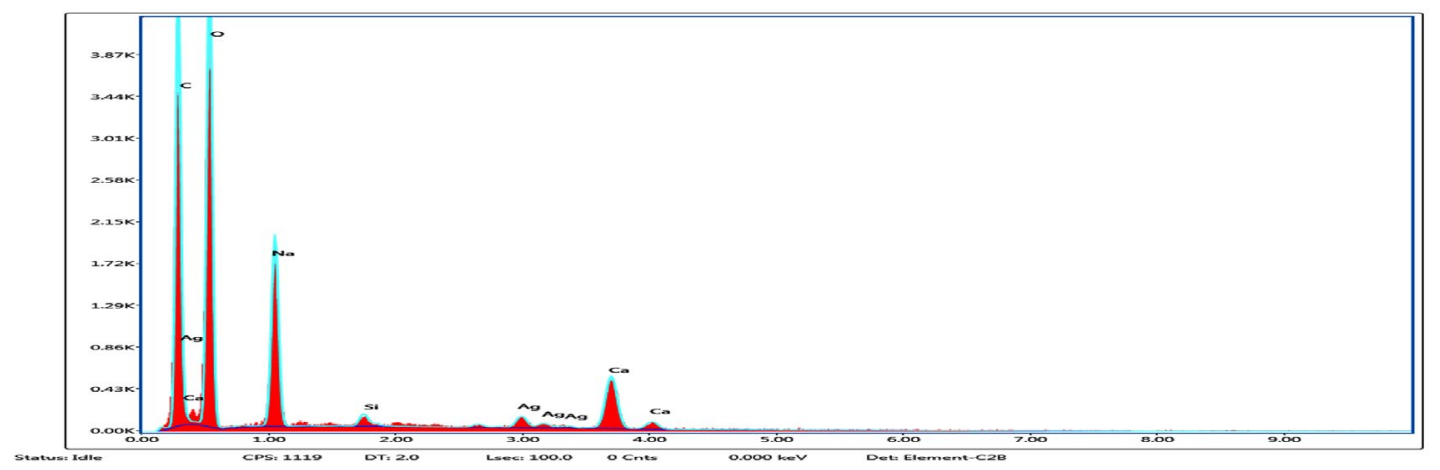

Fig. 5. EDAS analysis of chitosan nanocomposite. 


\section{EDAS}

EDAS is an important technique to identify the elemental composition of the synthesised sample. All the elements have its own atomic structures producing a unique set of peaks in X-ray spectrum which can be used for the identification of the element composition (Fig.5). The chitosan silver nanocomposites were showing different elements of Carbon (22.36\%), Oxygen (38.15\%), Sodium (13.66\%), Silicon (1.2\%), silver (17.85), Calcium (6.78\%). Lovejoy et al, reported that the elemental composition of the sample or a material identifying with EDAS analysis denotes the presence unique elements with weight and atomic concentration. ${ }^{27}$

There for in EDAS study, presence of silver and the other elements of carbon and oxygen signals are due to the chitosan that surrounds the silver nanoparticle while its get synthesised. ${ }^{28}$ Other study quantified the presence of elements such as silver (1.36\%) sulfur (0.84\%), silicon (67.74\%) and oxygen (30.07\%) from the synthesised chitosan composite, ${ }^{29}$ these resembles our findings.

XRD

Examination of XRD is an essential method to identify the crystalline structure of the nanoparticle along with the identification of phase composition and presence of impurities. Modrzejewska et al stated that the adsorption of $\mathrm{Ag}+$ ions changes crystalline or the fibrous structure of the chitosan polymer when it get synthesised..$^{25}$ The $\mathrm{X}$-ray analysis revealing the $\mathrm{Ag}$ metal ions and the degree of ordering of the tested sample is reduced because of the adsorption and synthesis of silver nanocomposites. ${ }^{23}$ The numbers of reflections with $2 \theta$ values of $38.53^{\circ}, 44.67^{\circ}$, $65.08^{\circ}$ and $78.06^{\circ}$ are corresponding to (1 111 ), (2 00 ), (220) and (3 11 1), which indicating the AgNPS spherical structure and crystalline nature.

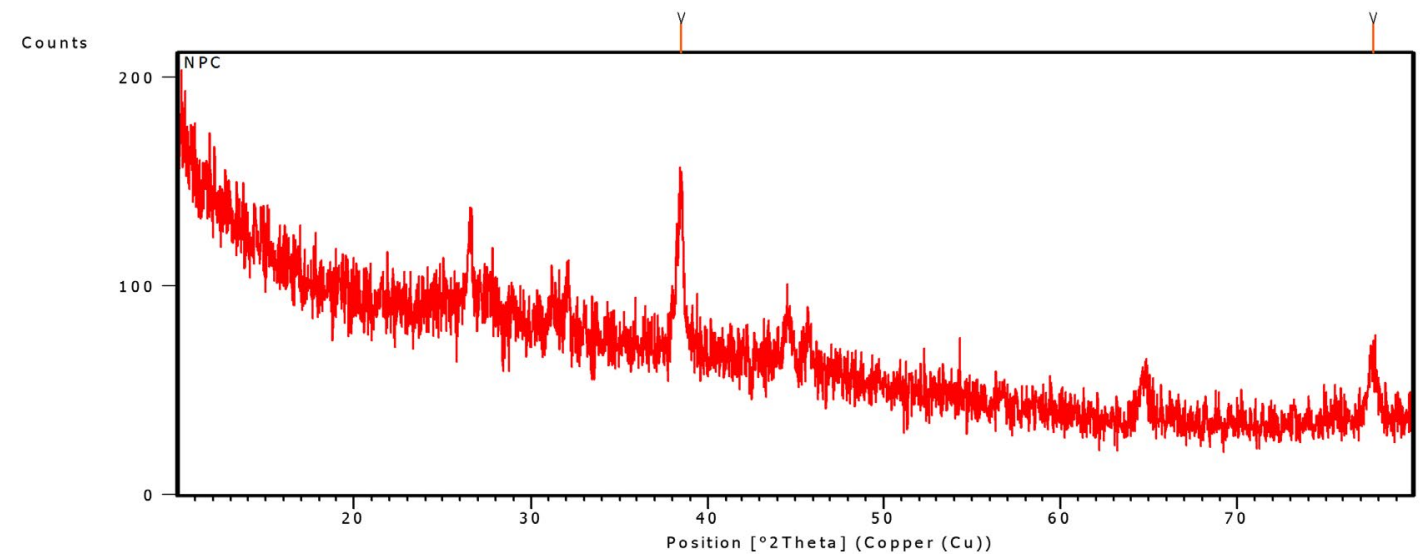

Fig. 6. XRD analysis of chitosan nanocomposite.

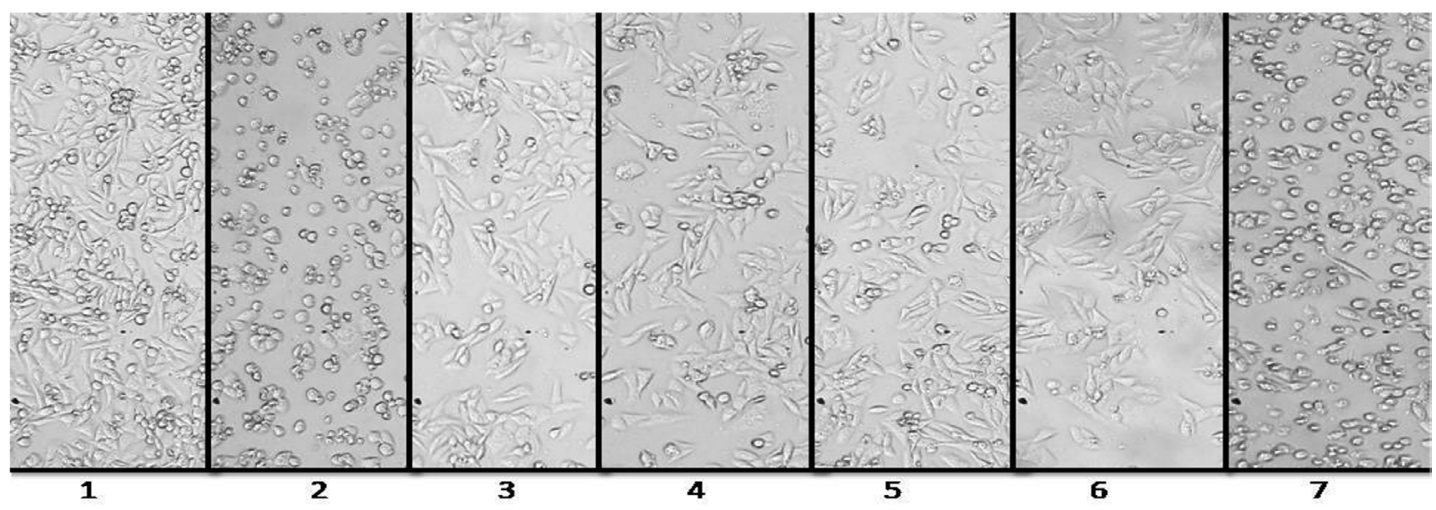

Fig. 7. ЗТ3 Cell Line under microscope; 1 -Control Cell Line, 2 -standard drug, 3-25 $\mu \mathrm{g}, 4-50 \mu \mathrm{g}, 5-100 \mu \mathrm{g}, 6-200 \mu \mathrm{g}$, 7-400 $\mu \mathrm{g}$ of sample treated against 3T3 Cell Line. 


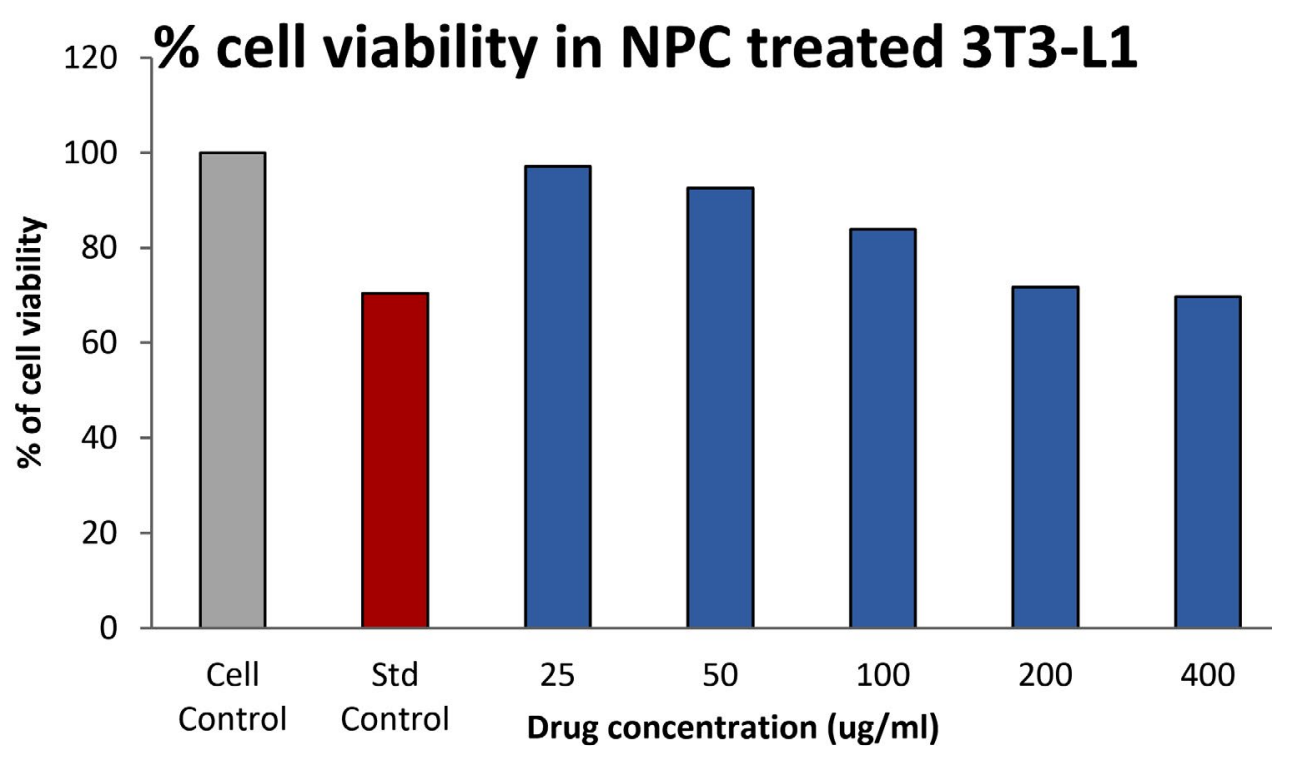

Fig. 8. Percentage of viable cells observed after treatment.

The sharp peak indicates bioactive compounds in the chitosan nanocomposite. Structural properties of the synthesized chitosan silver nanocomposite is clear from Fig. $6,{ }^{\circ} 2 \mathrm{Th}$ was observed at 38.47 and 77.67 with the height of 77.87 and 27.32 respectively (Fig. 6). Chitosan peaks were obtained at $2 \mathrm{~h}$ values of 11.7 , and 19.8 and silver peaks were pick up at $37.9,44.0$ and 63.9 , respectively. In another study, ${ }^{15}$ peaks were observed for chitosan at $2 \theta=10.1^{\circ}$ and $2 \theta=19.9^{\circ} .{ }^{30}$ The peak at $2 \theta=19.9^{\circ}$ indicated the high degree of chitosan and their crystal lattice constant and answering to 4.4. The numbers of Bragg mirroring of distinct peaks at $38^{\circ}, 44.1^{\circ}, 64^{\circ}$ and $77^{\circ}$ specify the miller indices (111), (200), (220) and (311) reflections of metallic silver represented the face-centered cubic crystalline structure of silver. ${ }^{18}$

\section{Toxicity study}

The toxicity study of the chitosan nanocomposites was done using the 3T3-L1 Cell Line employing MTT assay method. ${ }^{31}$ The increasing interest in the use of natural source as a remedial measure against obesity is because of the presence of chemical compounds in the commercial drugs and leads to some sideeffects. For this reason, anti-obesity agents from natural products are being studied and to be commercialised. As for chitin/chitosan-derived biomaterials, conflicting reports have recently been reported because of the anti-obesity effects.
Another study reported that the chitosan and Chitosan Oligosaccharide supplementation are helping to decrease the plasma cholesterol and increased cholesterol excretion in over weight normocholesterolemic humans. ${ }^{32}$

From the Fig. 8, the toxicity effect of the chitosan nanocomposite was found to be non toxic. $25,50,100,200,400 \mu \mathrm{g} / \mathrm{ml}$ chitosan nanocomposite shown $97.09 \pm 0.009,92.54 \pm 0.006$, $83.94 \pm 0.005,71.680 .004,69.65 \pm 0.001$ percentage of cell viability with the $620 \mu \mathrm{g} / \mathrm{ml}$ of $\mathrm{IC}_{50}$ value. The standard doxorubicin $(12.5 \mu \mathrm{g} / \mathrm{ml})$ shows $72 \%$ of cell viability.

Sumiyoshi and Kimura ${ }^{33}$ investigated the positive roles of chitosan for hypocholesterolemic effects in mice. Ranjitha et al, reported Terminalia arjuna extract has been found 98.55 to $90.88 \%$ $(10 \mu \mathrm{g}$ to $320 \mu \mathrm{g} / \mathrm{ml})$ of viable cells compare with untreated 3T3-L1 Cell Line. ${ }^{34}$

\section{CONCLUSION}

Our previous publication was detailed about the extraction of chitosan from the Pleurotus floridanus and Pleurotus djamor. ${ }^{12}$ The current research work was focused on the biogenic synthesis of chitosan $\mathrm{AgNO}_{3}$ nanocomposites. Further, it was characterised and tested against the 3T3 L1 Cell Line and found that the synthesised nanocomposite was non toxic. In UV -Visible spectrophotometer study, peak maxima was 
observed at 460nm, and FTIR also showed different functional group and confirmed the synthesis of silver nanocomposite. Size and morphology of the nanocomposites were determined with FESEM and XRD, 50.24 to $88 \mathrm{~nm}$ of size was observed with spherical in shape. Carbon (22.36\%), Oxygen (38.15\%), Sodium (13.66\%), Silicon (1.2\%), silver (17.85), Calcium (6.78\%) were observed in EDAS analysis. The nanocomposites exhibited $69.65 \%$ of viable cells and non toxic to 3T3-L1 Cell Line at the higher concentration $(400 \mu \mathrm{g} / \mathrm{ml})$. Further research is needed to improve and find the various application of the chitosan nanocomposites in food industry and other pharmaceutical effects.

\section{ACKNOWLEDGMENTS}

The authors are thankful to their representative University and Institute/College for providing the related support and facilities to compile this research work.

\section{CONFLICT OF INTEREST}

The authors declare that there is no conflict of interest.

\section{AUTHORS' CONTRIBUTION}

All authors listed have made a substantial, direct and intellectual contribution to the work, and approved it for publication.

\section{FUNDING}

None.

\section{DATA AVAILABILITY}

All data generated or analyzed during this study are included in the manuscript.

\section{ETHICS STATEMENT}

This article does not contain any studies with human participants or animals performed by any of the authors.

\section{REFERENCES}

1. Angulo FJ, Heuer OE, Hammerum AM, Collignon $P$, Wegener HC. Human health hazard from antimicrobialresistant enterococci in animals and food. Clin Infec Dis. 2006;43(7):911-916. doi: 10.1086/507534

2. Cantas L, Syed QA, Cavaco LM, et al. A brief multidisciplinary review on antimicrobial resistance in medicine and its linkage to the global environmental microbiota. Front Microbiol. 2013;4:96. doi: 10.3389/

\section{fmicb.2013.00096}

3. Williams $\mathrm{D}$. The relationship between biomaterials and nanotechnology. Biomaterials. 2008;29(12): 17371738. doi: 10.1016/j.biomaterials.2008.01.003

4. Sharma VK, Yngard R, Lin Y. Silver nanoparticles: Green synthesis and their antimicrobial activities. Adv Colloid Interface Sci. 2009;145(1-2):83-96. doi: 10.1016/j. cis.2008.09.002

5. Huang $\mathrm{H}$, Yang Y. Preparation of silver nanoparticles in inorganic clay suspensions. Compos Sci Technol. 2008;68(14):2948-2953. doi: 10.1016/j. compscitech.2007.10.003

6. Sriram MI, Kanth SBM, Kalishwaralal K, Gurunathan S. Antitumor activity of silver nanoparticles in Dalton's lymphoma ascites tumor model. Int J Nanomed. 2010;5(1):753-762. doi: 10.2147/IJN.S11727

7. El-Nour KMMA, Eftaiha A, Al-Warthan A, Ammar RAA. Synthesis and applications of silver nanoparticles. Arab J Chem. 2010;3(3):135-140. doi: 10.1016/j. arabjc.2010.04.008

8. Kumar MNVR. A review of chitin and chitosan applications. Reactive and Functional Polymers. 2000;46(1):1-27. doi: 10.1016/S1381-5148(00)000389

9. Gregori A, Svagel M, Pohleven, J. Cultivation techniques and medicinal properties of Pleurotus spp. Food Technology and Biotechnology. 2007;45(3):236-247.

10. Kalac P. Chemical composition and nutritional value of European species of wild growing mushrooms: a review. Food Chem. 2009;113(1):9-16. doi: 10.1016/j. foodchem.2008.07.077

11. Xu X, Yan H, Chen J, Zhang X. Bioactive proteins from mushrooms. Biotec Adv. 2011;29(6):667-674. doi: 10.1016/j.biotechadv.2011.05.003

12. Johney J, Sri SR, Ragunathan R. Extraction of chitin and chitosan from wild type Pleurotus spp and its potential application -Innovative approach. J Pure App/ Microbiol. 2018;12(3):1631-1640. doi: 10.22207/ JPAM.12.3.70

13. Alvarez SPO, Cadavid DAR, Sierra DME, et al. Comparison of extraction methods of chitin from Ganoderma lucidum mushroom obtained in submerged culture. Biomed Res Int. 2014;2014:169071. doi: 10.1155/2014/169071

14. Nisha V, Monisha C, Ragunathan R, Johney J. Use of chitosan as edible coating on fruits and in microbiological activity - an ecofriendly approach. Inter J Pharm Sci Inv. 2016;5(8):7-14.

15. Govindan S, Nivethaa EAK, Saravanan R, Narayanan $\mathrm{V}$, Stephen A. Synthesis and characterization of chitosan-silver nanocomposite. Applied Nanoscience. (2012)2:299-303. doi: 10.1007/s13204-012-0109-5

16. Phae-ngam W, Thamaphat K, Chutrakulwong F, Oopathump C. One-step green synthesis of chitosansilver nanoparticles. Suan Sunandha Sci and Tech J. 2017;4(1):19-23.

17. Devadiga BS, Shetty D, Lakshmi MSG, Packiyam JE, Bhat PR. Synthesis of chitosan silver nanoparticles from chitin of crustacean shells and its applications. Int J Curr Res Chem Pharm Sci. 2016;3(5):1-5.

18. Wang LS, Wang $\mathrm{CY}$, Yang $\mathrm{CH}$, et al. Synthesis and anti-fungal effect of silver nanoparticles-chitosan 
composite particles. Int J Nanomed. 2015;10(1):26852696. doi: 10.2147/IJN.S77410

19. Krishnaveni B, Ragunathan R. Extraction and Characterization of Chitin and Chitosan from F.solani CBNR BKRR, Synthesis of their bionanocomposites and study of their productive application. J Pharm Sci Res. 2015;7(4):197-205.

20. Honary S, Ghajar K, Khazaeli P, Shalchian P. Preparation, Characterization and antibacterial properties of silver-chitosan nanocomposites using different molecular weight grades of chitosan. Trop J Pharm Res. 2011;10(1):69-74. doi: 10.4314/tjpr.v10i1.66543

21. Al-Rasheed HH, Dahlous KA, Sholkamy EN, Osman SM, Abd-Elkader OH, El-Faham A. Chitosan-S-triazinyl-bis (2-aminomethylpyridine) and Chitosan S-triazinylbis (8-oxyquinoline) Derivatives: new reagents for silver nanoparticle preparation and their effect of antimicrobial evaluation. J Chem. 2020;2020:9590120. doi: 10.1155/2020/9590120

22. Paulkumar K, Gnanajobitha G, Vanaja M, Pavunraj M, Annadurai G. Green synthesis of silver nanoparticle and silver based chitosan bionanocomposite using stem extract of Saccharum officinarum and assessment of its antibacterial activity. Adv Nat Sci Nanosci Nanotechnol. 2017;8:035019. doi: 10.1088/20436254/aa7232

23. Kalaivani $\mathrm{R}$, Maruthupandya $\mathrm{M}$, Muneeswaran $\mathrm{T}$, et al. Synthesis of chitosan mediated silver nanoparticles (Ag NPs) for potential antimicrobial applications. Front Lab Med. 2018;2(1):30-35. doi: 10.1016/j.flm.2018.04.002

24. Gocho H, Shimizu H, Tanioka A, Chou T J, Nakajima T. Effect of polymer chain end on sorption isotherm of water by chitosan. Carbohyd Polym. 2000;41(1):87-90. doi: 10.1016/S0144-8617(99)00113-7

25. Modrzejewska Z, Dorabialska M, Zarzycki R, WojtaszPajak A. The Mechanism of sorption of Ag+ ions on chitosan microgranules: IR and NMR studies. Prog. Chem. Chitin Deriv. 2009;14:49-64.

26. Ryan C, Alcock E, Buttimer F, et al. Synthesis and characterisation of cross-linked chitosan composites functionalised with silver and gold nanoparticles for antimicrobial applications. Science and Technology of Advanced Materials. $2017 ; 18(1): 528-540$. doi: 10.1080/14686996.2017.1344929

27. Lovejoy TC, Ramasse QM, Falke M, et al. Single atom identification by energy dispersive $\mathrm{X}$-ray spectroscopy. Appl Phys Lett. 2012;100(15):154101. doi: 10.1063/1.3701598

28. Nate Z, Moloto MJ, Mubiayi PK, Sibiya PN. Green synthesis of chitosan capped silver nanoparticles and their antimicrobial activity. MRS Advances. 2018;3(4243):2505-2517. doi: 10.1557/adv.2018.368

29. Quintero-Quiroz C, Botero LE, Zarate-Trivino D, et al. Synthesis and characterization of a silver nanoparticlecontaining polymer composite with antimicrobial abilities for application in prosthetic and orthotic devices. Biomaterials Research. 2020;24(13). doi: 10.1186/s40824-020-00191-6

30. Dara PK, Mahadevan R, Digita PA, et al. Synthesis and biochemical characterization of silver nanoparticles grafted chitosan (Chi Ag NPs): in vitro studies on antioxidant and antibacterial applications. SN Appl. Sci. 2020;2(4):665. doi: 10.1007/s42452-020-2261-y

31. Huang $C$, Zhang $Y$, Gong $Z$, et al. Berberine inhibits 3T3-L1 adipocyte differentiation through the PPARgamma pathway. Biochem Biophys Res Commun. 2006;348(2):571-578. doi: 10.1016/j.bbrc.2006.07.095

32. Gallaher DD, Gallaher CM, Mahrt GJ, et al. A glucomannan and chitosan fiber supplement decreases plasma cholesterol and increases cholesterol excretion in overweight normo cholesterolemic humans. J Am Coll Nutr. 2002;21(5):428-433. doi: 10.1080/07315724.2002.10719246

33. Sumiyoshi M, Kimura Y. Low molecular weight chitosan inhibits obesity induced by feeding a high-fat diet longterm in mice. J Pharm Pharmacol. 2006;58(2):201-207. doi: 10.1211/jpp.58.2.0007

34. Ranjitha B, Bhaskar D, Sathyamurthy B. Invitro studies on the effect of Terminalia arjuna in adipocyte 3 T3 - L1 Cell Lines. Pharma Tutor. 2018;6(8):17-26. doi: 10.29161/PT.v6.i8.2018.17 